\title{
Electrospinning of Gelatin/Poly (Vinyl Pyrrolidone) Blends from Water/Acetic Acid Solutions
}

\author{
Tais Helena Costa Salles ${ }^{a}$, Christiane Bertachini Lombello ${ }^{b}$ Marcos Akira d'Ávila ${ }^{a *}$
}

\author{
${ }^{a}$ Departamento de Engenharia de Manufatura e Materiais, Faculdade de Engenharia Mecânica, \\ Universidade Estadual de Campinas - UNICAMP, Rua Mendeleyev, 200, CEP 13083-860, \\ Cidade Universitária "Zeferino Vaz" Barão Geraldo, Campinas, SP, Brazil \\ ${ }^{b}$ Centro de Engenharia, Modelagem e Ciencias Sociais Aplicadas - CECS, \\ Universidade Federal do ABC - UFABC, Rua Arcturus, 03, CEP 09606-070, Santo André, SP, Brazil
}

\author{
Received: July 16, 2014; Revised: April 28, 2015
}

\begin{abstract}
Electrospinning is a versatile and efficient technique for obtaining polymeric microfibers and nanofibers with great potential for applications in tissue engineering, biosensors, filtration, wound dressings, controlled drug release and enzyme immobilization. Electrospun fibers are obtained by applying an electric field in a polymer solution resulting in non-woven fibrous mats with high surface area relative to volume and high porosity. In this work, the electrospinning of gelatin/poly(vinyl pyrrolidone) (PVP) blends was investigated. The polymers were electrospun from solutions containing different concentrations of water and acetic acid. Solutions were characterized by measuring the $\mathrm{pH}$, electrical conductivity, surface tension and viscosity. The influence of acetic acid concentration in solution properties and its influence in the spinnability were investigated. The resulting non-woven membranes were characterized by using scanning electron microscopy (SEM), thermogravimetric analysis (TG) and cytotoxicity.
\end{abstract}

Keywords: electrospinning, gelatin, PVP, tissue engineering, biomaterials

\section{Introduction}

The artificial replacement of damaged and diseased tissues is a promising avenue of research in the field of regenerative medicine. Tissue engineering is a multidisciplinary field which aims tissue regeneration by using biomaterials ${ }^{1}$. Recently, the study of micro and nanofibers have attracted great interest due to their properties such as large surface to volume ratio and ability to form fibers ${ }^{2,3}$.

Electrospinning has been recognized as a versatile technique for obtaining micrometer and nanometer fibers, since it is possible to obtain fibers with a wide range of polymers, both natural and synthetic, as well as combinations of both polymers ${ }^{3-8}$. Electrospinning plays an important role for manufacturing fibrous biomaterial scaffolds for tissue engineering applications with fiber diameters ranging from few microns to less than $100 \mathrm{~nm}$. These materials, such as proteins (gelatin, collagen and silk fibroin) and polysaccharides (chitosan, hyaluronic acid and cellulose) can be designed to mimic the extracellular matrix due to the fibrous structure with diameters in micrometer and nanometer scales ${ }^{1,3,7,9}$. Applications can be found in a wide variety of biomedical applications such as scaffolds for tissue engineering, , wound dressings and drug delivery systems ${ }^{1-3,5,7,8,10-13}$.

Basically, four components are required for polymer solution electrospinning: a high voltage supply; a capillary tube, which can be a small diameter needle; an infusion pump, and a grounded collector plate ${ }^{2,3}$. One electrode is attached to a needle connected to a syringe filled with the

*e-mail:madavila@fem.unicamp.br polymer solution, whereas the other is fixed to the collector connected to ground. The electric field is applied to the end of the capillary tube containing the fluid that induces an electric charge on the liquid surface, resulting in a force opposite to the surface tension. As the electric field intensity is increased, the fluid surface at the tip of the capillary tube elongates to form a conical shape known as Taylor cone ${ }^{11-14}$. The jet is stable only at the region close to the tip of the needle, after which jet instabilities are observed. In the jet trajectory from the needle to the collector, the solvent evaporates and dry fibers are deposited on the collector plate as an interconnected network ${ }^{1,11,15}$. The collected fibers are typically in the form of a blanket ${ }^{5,7,11}$. Figure 1 shows a scheme of an electrospinning system.

The electrospinning process depends on many parameters, classified broadly into solution, process and environmental parameters. These parameters can influence the processing of polymer solutions into fibers by electrospinning ${ }^{1,5,10,16}$. The main solution parameters are viscosity, surface tension and electrical conductivity; whereas the main process parameters are applied voltage, flow rate and distance from the needle tip to the collector plate. Environmental parameters include temperature and humidity of the environment ${ }^{1,11,13,17}$.

Polymeric materials are widely applied in the biomedical area. Although it is much easier to obtain electrospun fibers from synthetic polymers, natural polymers are desired due to its biocompatibility and biodegradability ${ }^{18}$. One can use blends of synthetic and natural polymers, aiming the 
development of new materials with properties intermediate or even superior to those observed in pure constituents ${ }^{9}$.

Gelatin is a derivative of collagen obtained by denaturing its triple helical structure ${ }^{13,19}$. There are two types of gelatin extracted from collagenous tissue: Type A, which is pre-processed by acid treatment; and Type $\mathrm{B}$, which is pre-processed by an alkaline treatment. The main difference between the two is that type B has higher carboxylic acid content than type A. The molecular weight distribution of type A and B gelatin is slightly different. Type B gelatin usually has a greater proportion of high molecular weight fractions, while type A has a more homogeneous distribution, containing larger amount of low molecular weight polypeptides ${ }^{20}$.

Due to the similarities between collagen and gelatin, the latter became an attractive polymer for applications in tissue engineering ${ }^{21}$. Electrospun gelatin mats have been used for different applications such as artificial skin, bone graft substitutes, cartilage, blood vessels, and tendon implants. In medicine, gelatin can be used as sponges and bleeding stakes which are then absorbed by the human body ${ }^{5,13,18,22}$.

The ideal solvent for gelatin for medical applications is water in the absence of toxic residues. However, at room temperature gelatin is partially soluble in water and usually presents high viscosity, which makes it not suitable for electrospinning. This occurs because at room temperature there is an increase in hydrogen bonding, which leads to a transition in the individual helices that were separated in the collagen denaturation. The helices rearrange themselves over time to form a three-dimensional gel network ${ }^{23}$. Therefore, in order to obtain electrospun gelatin mats at room temperature, it is necessary to use other solvents in order to achieve solution properties that are suitable for electrospinning.

Some studies on gelatin electrospinning reported that nanofibers were obtained from solutions using solvents such as 1,1,1,3,3,3-hexafluoro-2-propanol (HFP), 2,2,2-trifluoroethanol (TFE) that can be used to dissolve natural polymers ${ }^{6,24,25}$. However, these solvents are highly toxic and residues of these solvents in which the fibers where electrospun may be released by degradation in the body and be detrimental to the host. Thus acid aqueous systems are preferable for biomedical applications such as water / formic acid and water / acetic acid ${ }^{25}$

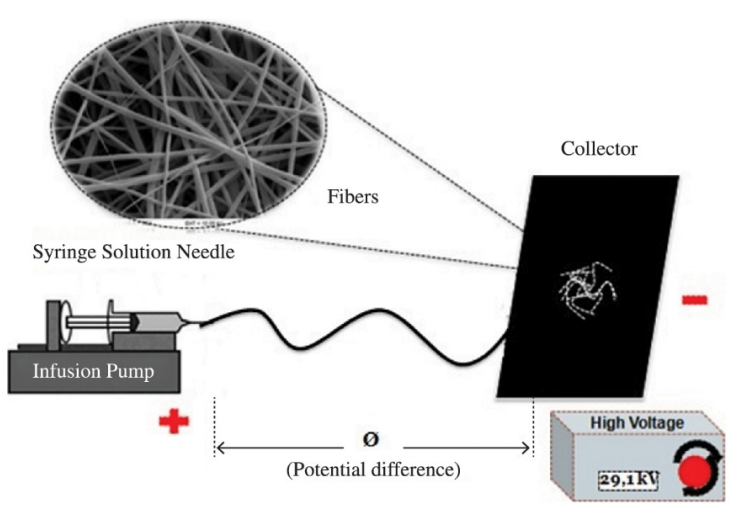

Figure 1. Schematic representation of the typical assembly of an electrospinning apparatus.
Poly(vinyl pyrrolidone) (PVP) is a synthetic polymer, water soluble, biocompatible, hemocompatible and has been applied as a biomaterial for many years ${ }^{26}$. PVP is remarkable due to its ability to interact with a wide variety of hydrophilic and hydrophobic materials and has properties similar to those of a protein due to its pyrrolidone structure. This material exhibits low immunogenicity, antigenicity and very low toxicity ${ }^{27-29}$. This material is used in a wide variety of applications and it is interesting from a biological point of view, since it has structural features similar to those of proteins, and has great potential for applications in the medical field ${ }^{28-30}$.

Gelatin and PVP are miscible and have interesting biological properties because the mixture of collagen/PVP gives the possibility of producing new materials for the treatment of wound healing ${ }^{31,32}$. These materials are miscible due to the strong interactions between the synthetic and biological component, mainly due to hydrogen bonds. PVP can be used in the preparation of membranes and fibers in the electrospinning process in order to adjust the morphology, solution viscosity, size and size distribution of pores, increase the permeability of the membrane, and prevent the formation of defects ${ }^{24,29}$.

This study investigated the electrospinning of gelatin / PVP blends from of acetic acid/water solutions. The effect of acetic acid concentration in the solution properties and in the fiber morphology was investigated. The use of acetic acid in the solutions ensured obtaining solutions with properties suitable for electrospinning. It was found that the average diameters of the resulting fibers vary depending on the solvent composition. The solutions properties such as viscosity, surface tension, electrical conductivity and $\mathrm{pH}$ were measured. The morphology of the membranes was evaluated by Scanning Electron Microscopy (SEM) and analyzed by thermogravimetric analysis (TG). Cytotoxicity of gelatin/PVP mats was evaluated with Vero cells.

\section{Material and Methods}

The materials used in this study were gelatin type B from bovine skin (Sigma Aldrich), PVP (MW = 360,000, Sigma Aldrich), acetic acid $\left(\mathrm{CH}_{3} \mathrm{COOH}, 99.7 \%\right.$ Ecibra $)$ and deionized water. Solutions were prepared in different mass ratios of water/acetic acid, without any treatment or purification. Polymer solutions were prepared by dissolving $9.2 \%$ by weight of gelatin and $7.4 \%$ by weight of PVP at various concentrations of water/ acetic acid. Compositions of each solution are shown in Table 1. All solutions were stirred for 2 hours (Nova Ética agitator, Model 114) at $26^{\circ} \mathrm{C}$ and electrospun at the same day of preparation.

\subsection{Solution characterization}

All polymer solutions were characterized by measuring $\mathrm{pH}$, viscosity, surface tension and electrical conductivity. The $\mathrm{pH}$, electrical conductivity and surface tension were measured using a digital $\mathrm{pH}$ meter (Digimed, Model MD-22), a digital conductivity meter (Digimed, Model DM-32) and a ring tensiometer (Krüss, K-12 and Sigma, 701), respectively. For each solution, average values of these properties were obtained from at least three measurements. 
Solution viscosity as a function of the shear rate was measured using a Haake RS1 rheometer, with cone and plate geometry PP35Ti (size $35 \mathrm{~mm}$ ) in steady shear, with shear rates from 0.01 to $100 \mathrm{~s}^{-1}$. All measurements were performed at $25^{\circ} \mathrm{C}$.

\subsection{Electrospinning}

Electrospinning was performed at room temperature, using a $10 \mathrm{ml}$ disposable syringe with a metal needle of $0.55 \mathrm{~mm}$ internal diameter. The positive pole of the high voltage supply $(0-30 \mathrm{kV}$, Testtech) was connected to the tip of the metallic needle of the syringe, while the ground electrode was used to ground the copper collector plate with dimensions of $5.0 \times 10.0 \mathrm{~cm}$. The flow rate was controlled by an infusion pump (KD-Scientific, KDS Model-100), connected to the syringe. The distance from the needle tip to the collector was $10 \mathrm{~cm}$. Solutions were processed with voltage of 27.1 to $27.2 \mathrm{kV}$ and flow rate of $1 \mathrm{~mL} / \mathrm{h}$. Electrospun mats were collected on a copper plate covered with aluminum foil. In each test, approximately $5 \mathrm{ml}$ of the polymer solution were used.

\subsection{Characterization of electrospun membranes}

Scanning electron microscopy-SEM (Zeiss, Evoma-15) was used to analyze gelatin/PVP electrospun fibers. Samples were coated with gold using a Sputter Coater equipment (Bal-Tec, $\mathrm{SCD}-\mathrm{O5O}$ ). Average fiber diameters were determined from SEM images using the image analysis software ImageJ from at least 50 measurements randomly chosen.

Thermogravimetric analysis TG was performed using samples of approximately $10 \mathrm{mg}$ using a STA 409C (Netzsch, Germany). The carrier gas was nitrogen, at a flow rate of $50 \mathrm{~mL} / \mathrm{min}$. The samples were heated from 18 to $500^{\circ} \mathrm{C}$ in a single heating rate of $10^{\circ} \mathrm{C} / \mathrm{min}$.

\subsection{Cytotoxicity}

Tests for indirect cytotoxicity of the biomaterial gelatin/PVP fluid extract were performed according to the ISO-10993-5 ${ }^{[33]}$ standard. Vero cell line (Adolfo Lutz/São Paulo) were cultured in medium 199, with $10 \%$ fetal bovine serum and $10 \%$ antibiotic solution (penicillin / streptomycin), and were maintained at $37^{\circ} \mathrm{C}$ and $5 \% \mathrm{CO}_{2}$.

Samples were sterilized using ethylene oxide according to ISO $11135^{[34]}$ standard and incubated in culture medium for 24 hours to obtain the fluid extract. The cell seeding was performed with density of $3 \times 10^{3}$ cells/well, in culture plates of 24 wells. Cells were cultured for 24 hours in this

Table 1. Solution concentration of water/acetic acid (wt\%)

\begin{tabular}{cc}
\hline Sample & $\begin{array}{c}\text { Acetic acid concentration } \\
(\mathbf{w t} \%)\end{array}$ \\
\hline 1 & 9.3 \\
2 & 18.6 \\
3 & 27.8 \\
4 & 37 \\
5 & 46.3 \\
6 & 55.5 \\
7 & 64.8 \\
\hline
\end{tabular}

condition until reaching approximately $80 \%$ monolayer confluence. Then the culture medium was replaced by the extraction fluid. As a negative control (not cytotoxic) the standard culture medium was used, and as positive control (cytotoxic) a phenol solution $0.4 \%$ in culture medium was used. The tests were performed in triplicate.

After 24 hours of incubation the cell morphology was evaluated by phase contrast microscopy. The analysis were complemented by cell fixation in glutaraldehyde $(2.5 \%)$, followed by staining with Toluidine Blue $0.1 \%$. Observations were made by inverted light microscopy (A1 Axiovert, Zeiss).

For the observation of the cells in direct contact with the biomaterial the culture conditions and processing was the same described above.

\section{Results and Discussion}

Figure 2 shows a plot of $\mathrm{pH}$ versus acetic acid concentration, showing that the $\mathrm{pH}$ decreases monotonically with increasing acetic acid concentration from 3.3 to 1.9 . This behavior was expected, since the concentration of hydrogen ions $\left(\mathrm{H}^{+}\right)$is higher in the acidic environment ${ }^{35}$. Monitoring the solution $\mathrm{pH}$ is important since gelatin can degrade in acidic environment at $\mathrm{pH}$ less than $1.5^{[6]}$ Thus, the solutions used in this work presented admissible $\mathrm{pH}$ values.

Figure 3 shows a plot of surface tension versus acetic acid concentration. It can be seen that the surface tension varied between $33 \mathrm{mN} / \mathrm{m}$ and $40 \mathrm{mN} / \mathrm{m}$, and presented a tendency to decrease with increasing the acetic acid concentration.

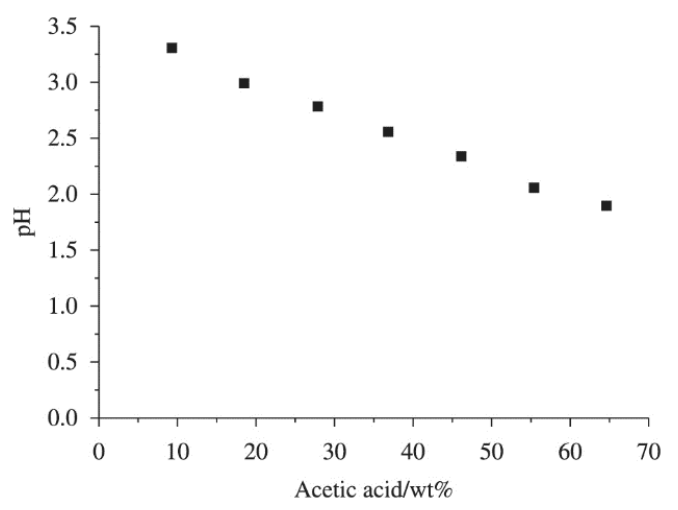

Figure 2. $\mathrm{pH}$ as a function of acetic acid concentration.

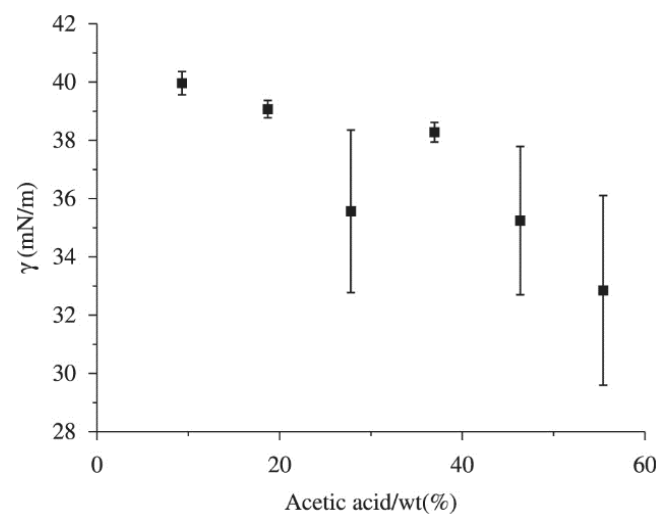

Figure 3. Surface tension as a function of acetic acid concentration in gelatin/PVP solutions. 
The decrease in surface tension with the increase of acetic acid concentration was expected since acetic acid has surface tension of about $28.8 \mathrm{mN} / \mathrm{m}$, while water has surface tension of about $72 \mathrm{mN} / \mathrm{m}$ at room temperature $\mathrm{e}^{6,36}$. However, there is evidence that the polymers also contributed to surface tension decrease. According to the literature, the water / acetic acid solution surface tension at a concentration range of 10 to $40 \mathrm{wt} \%$ have values of approximately 55.0 to 41.0 , respectively ${ }^{37}$. The influence of the polymers can be attributed to the fact that they might act as surfactants, being adsorbed at the interface, due to the fact that both gelatin and PVP has hydrophobic and hydrophilic molecular segments ${ }^{21,29}$.

Figure 4 shows a graph of electrical conductivity as a function of acetic acid concentration. It can be seen in the figure that the conductivity varied from $658.1 \mu \mathrm{S} / \mathrm{cm}$ and $2001.9 \mu \mathrm{S} / \mathrm{cm}$ and decreased with increasing acetic acid concentration. The decrease in electrical conductivity occurred differently to what was expected, due to higher concentration of $\mathrm{H}^{+}$ions in the solution ${ }^{36}$. However, it has been reported by Vieira et al. ${ }^{38}$ that the ionic conductivity decreases with higher levels of acetic acid, which can be due to the formation of multiple ions. On the other hand, there is also evidence that the polymers have an influence on the electrical conductivity of the solution, since this property is mainly determined by the type of polymer and solvent used $^{11,39}$.

Figure 5 shows a plot of viscosity $\eta$ versus shear rate. It can be observed that the viscosity presented a slightly shear thinning behavior at low shear rates $\left(<1 \mathrm{~s}^{-1}\right)$ and at high shear rates $\left(>10 \mathrm{~s}^{-1}\right)$. Newtonian behavior can be observed in the range of shear rates from 1 to $10 \mathrm{~s}^{-1}$.

A shear rate estimate at the exit of the capillary during the electrospinning process can be obtained from the internal diameter and flow rate given in the previous section. For a Poiseuille flow of a Newtonian fluid, the shear rate can be calculated by where $\mathrm{Q}$ is the flow rate and $\mathrm{R}$ is the internal diameter of the capillary. Therefore, the solution viscosity can be considered to be Newtonian, since at the end of the capillary, the characteristic shear rate is within the Newtonian range for all solutions.

Figure 6 shows the Newtonian viscosity $\eta_{N}$ as a function of acetic acid concentration. The Newtonian viscosity values were taken as an average value of viscosities at shear rates from 1 to $3 \mathrm{~s}^{-1}$.

It can be observed in Figure 6 that $\eta_{N}$ ranges from 0.42 to $1.45 \mathrm{~Pa} . \mathrm{s}$, and it tends to increase with increasing the concentration of acetic acid. However, $\eta_{N}$ of the solution with lower acid concentration (solution 1) is higher than $\eta_{\mathrm{N}}$ of solutions 2, 3 and 4. According to Davanço et al. ${ }^{40}$, the increased solution viscosity at acidic $\mathrm{pH}$ can be related to increased molecular aggregation.

Figure 7 shows a TG thermogram for pure gelatin and PVP. For pure gelatin, it can be observed a weight loss of $20 \%$ in the sample curve in the range of temperature of 18 to $100^{\circ} \mathrm{C}$ before initiating the degradation process, which corresponds to water evaporation present in the sample. Degradation starts at a temperature of approximately $250^{\circ} \mathrm{C}$ and proceeds up to $420^{\circ} \mathrm{C}$ with weight loss of approximately $70 \%$. In this process the samples undergo endothermic reactions of hydrolysis and oxidation ${ }^{41}$. In the final step above 420 to $500^{\circ} \mathrm{C}$ exothermic reactions occur at the end of pyrolysis derived collagen with a mass loss of $89 \%$ leaving around $11 \%$ ash formed by carbon residues ${ }^{41}$.

For pure PVP, TG curve shows an initial weight loss of about $20 \%$ from 18 to $80^{\circ} \mathrm{C}$, loss of water, the weight loss up to this temperature range is assigned to oligomers, low molecular weight, loss of moisture and residual solvent in

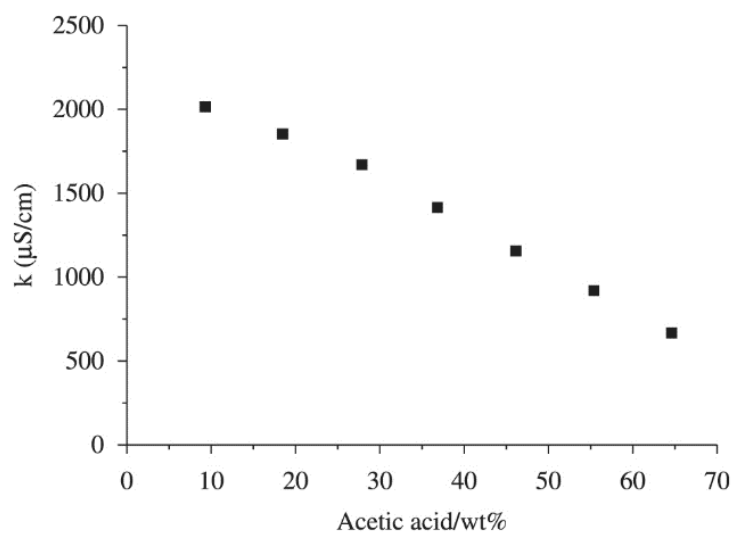

Figure 4. Solution electrical conductivity as a function of acetic acid concentration.

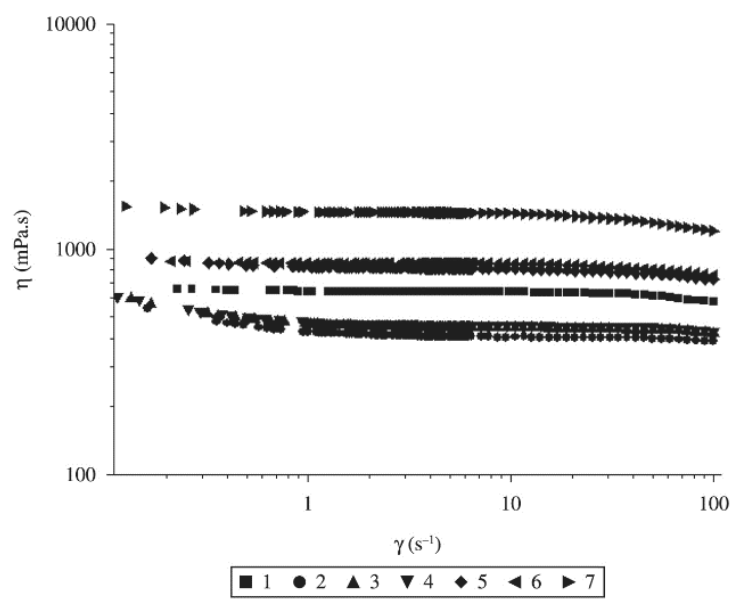

Figure 5. Viscosity as a function of shear rate of the solutions with different concentrations of acetic acid.

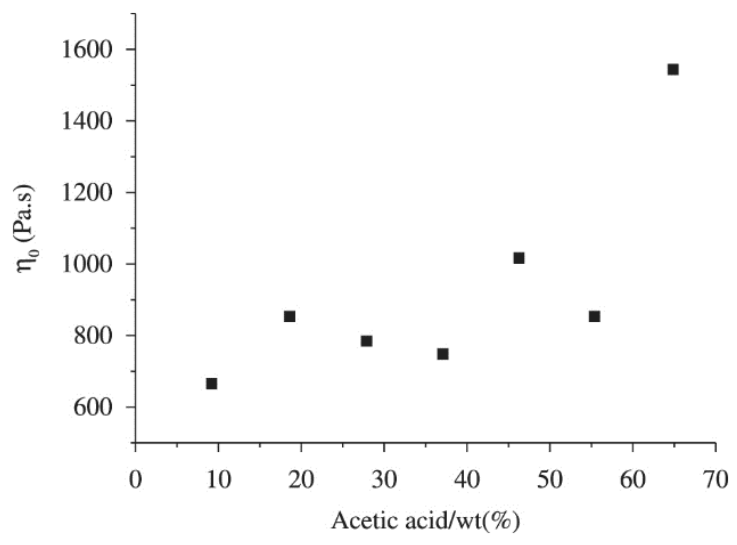

Figure 6. Zero-shear viscosity versus acetic acid concentration of gelatin / PVP 
this temperature range PVP degradation can be observed above $330^{\circ} \mathrm{C}$, where the weight loss can be attributed to decomposition of the structural polymer ${ }^{42}$.

Figure 8 shows the TG thermogram of electrospun gelatin/PVP membranes obtained from solutions 4 and 7 (see Table 1), which are the membranes used in the cytotoxicity tests. It can be observed that the decomposition begins at approximately $350^{\circ} \mathrm{C}$ and continues up to $480^{\circ} \mathrm{C}$. This shows that the thermal stability of the gelatin was improved due to the presence of PVP. This observation is consistent with the results observed in Figure 7, where it was shown that pure gelatin begins to decompose at about $250^{\circ} \mathrm{C}$ and the

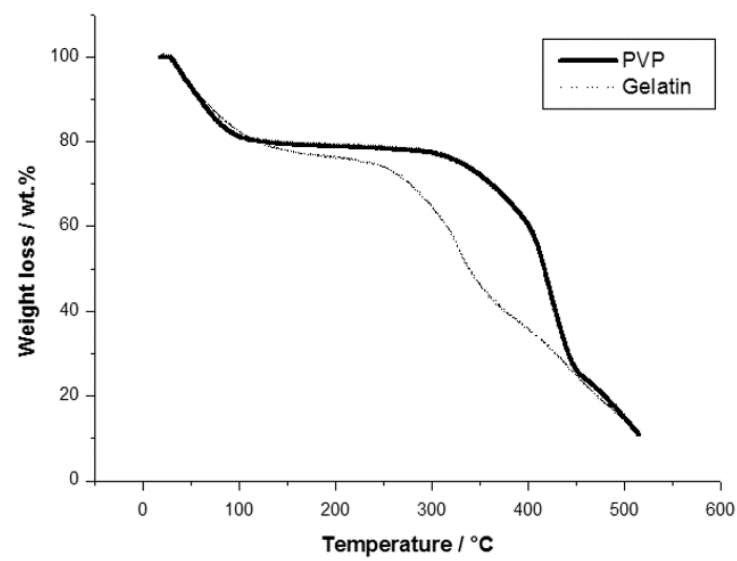

Figure 7. Thermogravimetric curves (TGA) of pure gelatin and pure PVP.

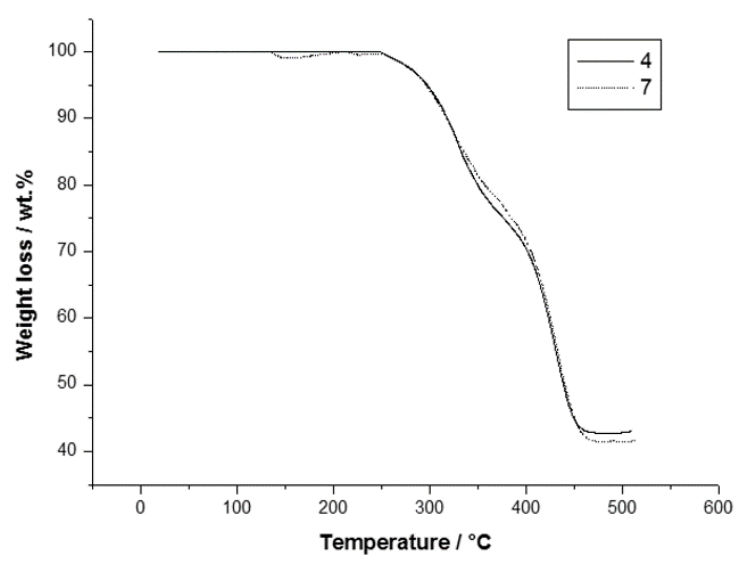

Figure 8. TGA thermal degradation of the polymer blend gelatin / PVP. polymer blends begin to decompose at higher temperatures above $350^{\circ} \mathrm{C}$. The improved thermal stability of the gelatin is attributed to the interaction between gelatin/PVP, thus leading to higher heat resistance of the resulting polymer blend in comparison with pure gelatin, such as reducing the mass loss of pure gelatin and PVP $11 \%$ to about $40 \%$ of the polymer blend.

Figure 9 shows SEM images of electrospun gelatin/PVP membranes. It can be observed that uniform fibers were obtained for solutions 4 (Figure 9d), 5 (Figure 9e) and 7 (Figure 9g). For electrospinning from solutions 1, 2 and 3 (Figures 9a-c, respectively) the formation of fibers in some regions was observed, but interconnected fibers in the area analyzed were not observed and it can also be observed the presence of defects. Interestingly, for the case of electrospinning from solution 6 (Figure 9f) it is observed an evidence of fiber formation, but complete solvent evaporation did not occur, leading to the dissolution of the fibers on the collector. It is also important to highlight that this spinning behavior was reproduced.

Figure 10 shows fiber diameter histograms from the electrospun membranes obtained from solutions 4, 5 and 7 (Figures 10a-c, respectively). It can be observed a decrease in average diameter with the decrease of acetic acid concentration. Also, it can be observed that in Figure 10a (solution 4) the histogram peak is in the range of $100-200 \mathrm{~nm}$, where in figure $10 \mathrm{~b}$ the peak is the range of 300-400 nm (solution 5), and in Figure 10c (solution 7) the peak is in the range of $480-510 \mathrm{~nm}$ with significant broader distribution.

It is known that high solution surface tension inhibits the electrospinning process, since jet instabilities lead to jet breakup in droplets ${ }^{43}$. From the results presented in Table 2, it can be seen that fibers were obtained for higher values of surface tension (solution 4), thus, it can be concluded that the surface tension, within the range of values obtained, was not the determining factor for the formation of fibers.

From Figures 5 and 6 and Table 2, it can be seen that the viscosity depends on the acetic acid concentration. Studies indicate that higher viscosity values often give rise to uniform fibers with larger average diameter due to polymer chain entanglements, which makes jet stretching more difficult ${ }^{1,17}$. However, as observed in Table 2, the solution with lowest viscosity (solution 7) resulted in fibers with larger diameters when compared with fibers obtained from solution 5, which has higher viscosity. Therefore, this

Table 2. Values of solution properties and the average diameter of the fibers gelatin / PVP obtained by electrospinning.

\begin{tabular}{cccccc}
\hline Number & $\mathbf{p H}$ & $\boldsymbol{\gamma}(\mathbf{m N} / \mathbf{m})$ & $\mathbf{k}(\boldsymbol{\mu S} / \mathbf{c m})$ & $\boldsymbol{\eta}_{\mathbf{0}}(\mathbf{m P a . s})$ & $\begin{array}{c}\text { Average diameter } \\
(\mathbf{n m}) *\end{array}$ \\
\hline 1 & 3.30 & 40.24 & 2001.9 & 662.3 & - \\
2 & 2.98 & 38.88 & 1839.4 & 846.6 & - \\
3 & 2.78 & 33.56 & 1661.2 & 782.2 & $154(38)$ \\
4 & 2.54 & 38.04 & 1409.2 & 746.6 & $355(121)$ \\
6 & 2.33 & 33.43 & 1138.5 & 1014 & - \\
7 & 2.04 & 30.53 & 916.1 & 851.9 & $519(192)$ \\
\hline
\end{tabular}

*The value in parentheses corresponds to the standard deviation. 


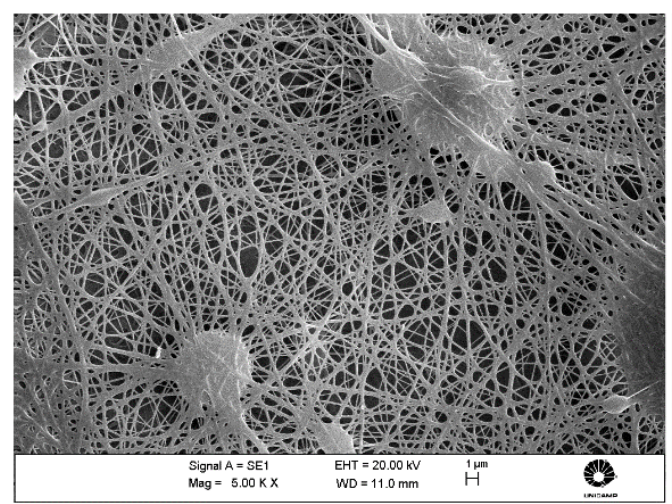

(a)

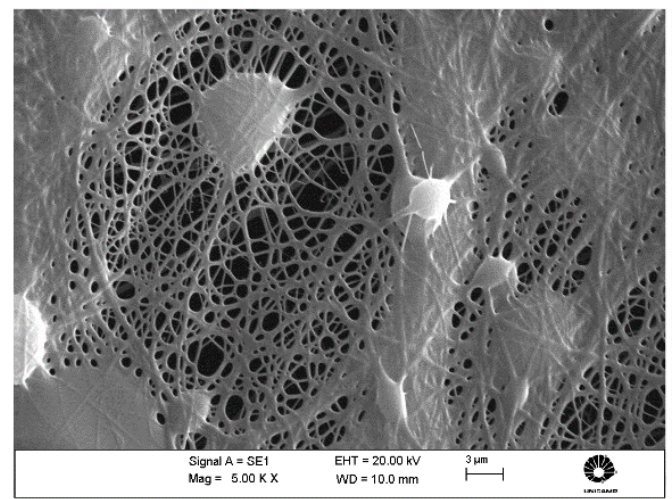

(c)

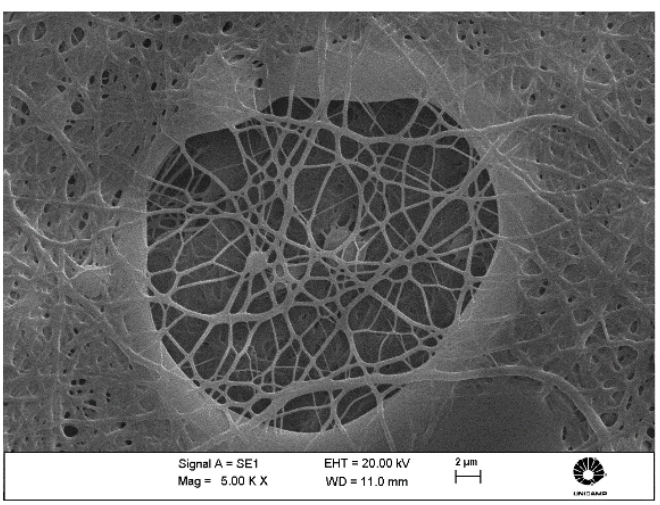

(b)

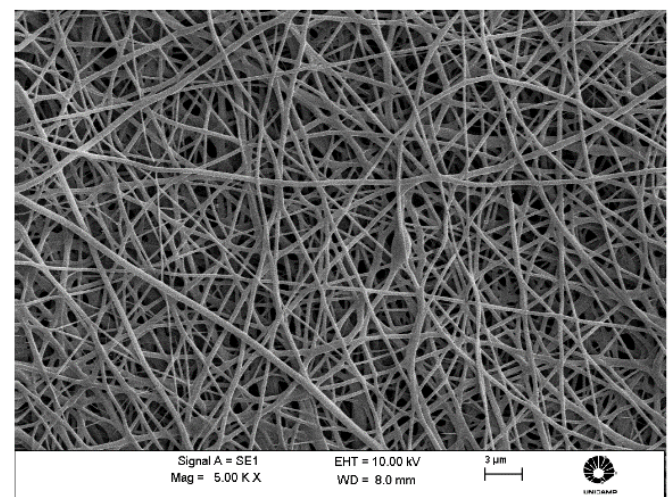

(e)

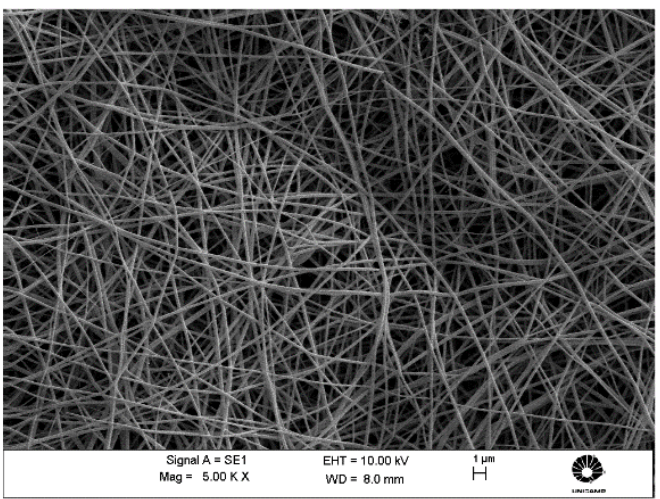

(d)

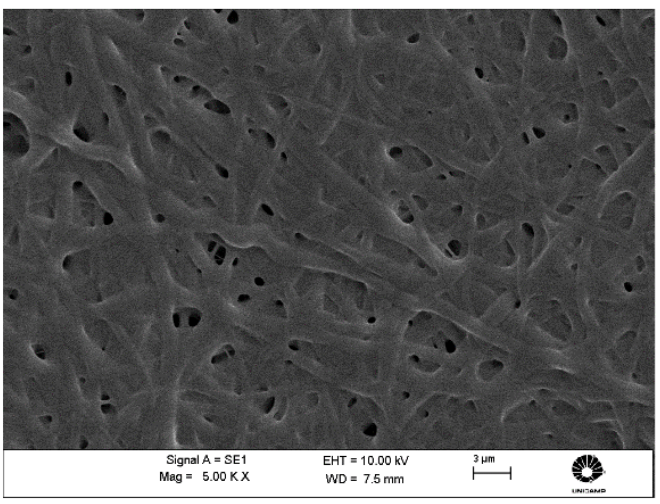

(f)

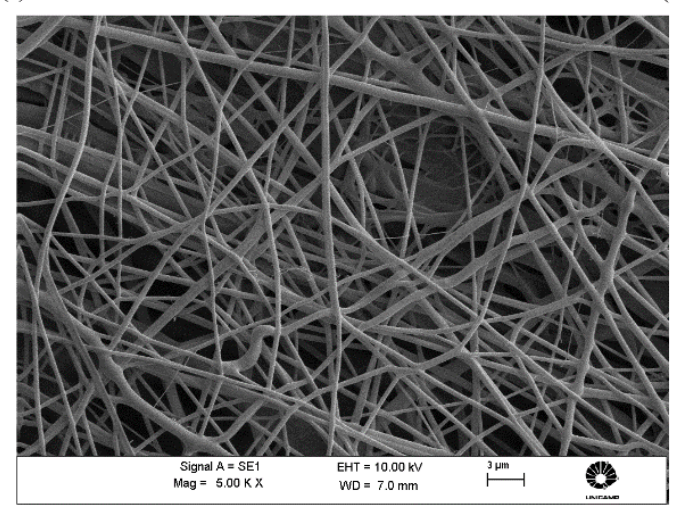

(g)

Figure 9. SEM images of the electrospun fibers from different solutions with magnification of 5000x: (a) 1 (9.3wt $\%)$, (b) 2 (18.6wt $\%)$, (c) 3 (27.8wt\%), (d) 4 (37.0wt\%), (e) 5 (46.3wt\%), (f) 6 (55.5wt\% and (g) 7 (64.8wt\%). 
result indicates that the viscosity was not the main solution property which determines the fiber diameter.

It can be seen in Table 2, that the average fiber diameter decreased with electrical conductivity increase, although for values of electrical conductivity above $1661.2 \mu \mathrm{S} / \mathrm{cm}$, the fibers were not uniform and had many defects. Thus, there is

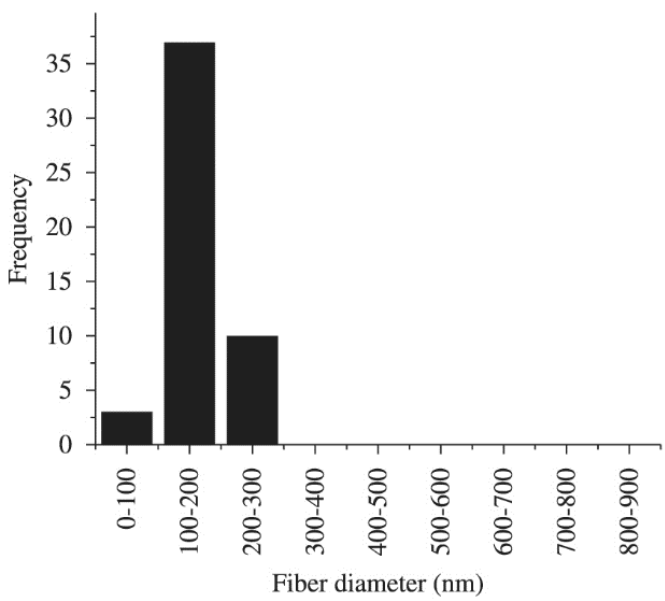

(a)

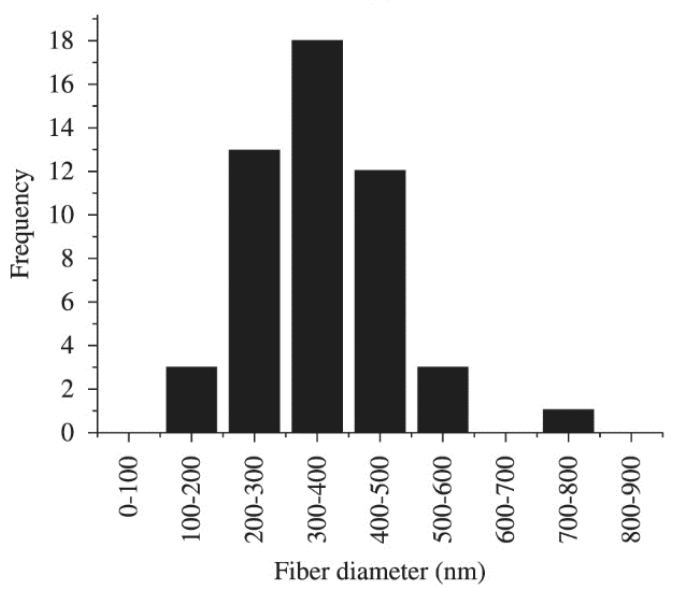

(b)

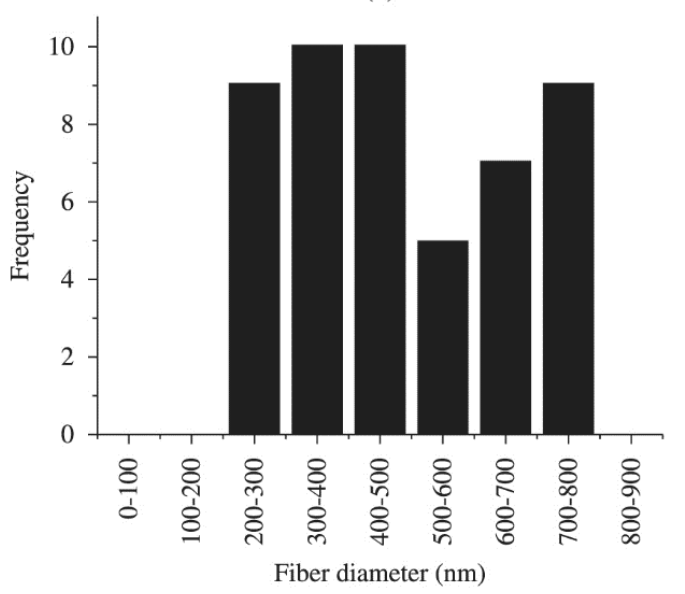

(c)

Figure 10. Histogram of fiber diameters of gelatin / PVP eletrofiadas. With different concentrations of acetic acid (\%) weight: (a) Solution 4 (37.0), (b) Solution 6 (46.3), (c) Solution 7 (64.8). a maximum limit for electrical conductivity in order to obtain uniform fibers, where above this limit jet breakup occurs.

From the results presented it can be concluded that the solution electrical conductivity, which depends on acetic acid concentration has a significant effect on the fiber formation and morphology.

Figure 11 shows a photograph of an electrospun gelatin/PVP membrane. Typical membranes presented dimensions of approximately $3.5 \times 3.5 \mathrm{~cm}$, and thickness of approximately $3 \mathrm{~mm}$.

In vitro cytotoxicity tests are made as an initial verification of the biomaterials biocompatibility evaluation, aiming future applications of a specific biomaterial in tissue engineering. The cytotoxicity is an in vitro technique that can be morphologically detected by cell observation, or can be measured quantitatively by cell lysis (cell death), the inhibition of cell growth and other possible effects on cells caused by the devices, materials and / or their extracts. In this investigation the morphology of cells exposed to elution biomaterial extracts was observed.

In Figure 12a it is noted a confluent monolayer scattered of cells, used as non cytotoxic control. We observed the basophilic cytoplasm and the individual nucleus, containing 1 to 3 nucleoli, typical of this cell line. In Figure 12b it can be observed that the solution of phenol showed cytotoxic effects, and in this condition the few cells were adhered to the culture plate, showing various extensions and very dense nucleus; it is not possible to identify the nucleoli, indicative of degeneration process. Debris were observed in the culture medium.

In Figure 13a and Figure 13c cultured cells provided indirect cytotoxicity which showed growth pattern expected to Vero cells, and consistent with non cytotoxic control. The cells had become quite spread, forming a confluent monolayer with fibroblastic appearance, well-defined nucleus and clear nucleolus identification. There was no cell debris or expressive cell degeneration. In Figure 13b and Figure 13d the same result can be observed in the test cell culture in direct contact with the biomaterial gelatin / PVP. The cells in the culture dish, and even in areas of direct contact with the biomaterial, kept the standard typical fibroblast without significant signs of degeneration and cell death ${ }^{44,45}$.

The growth of Vero cells in confluent monolayer with typical fibroblast morphology, and similar to non cytotoxic control, shows that the biomaterial gelatin / PVP can be

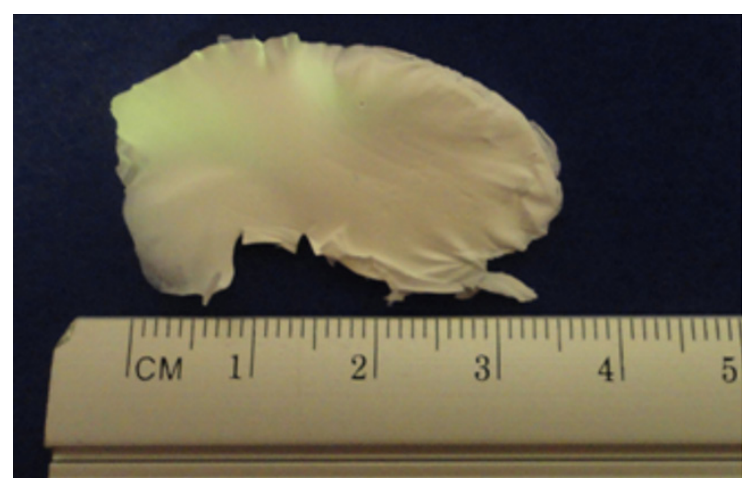

Figure 11. Electrospun gelatin/PVP membrane. 


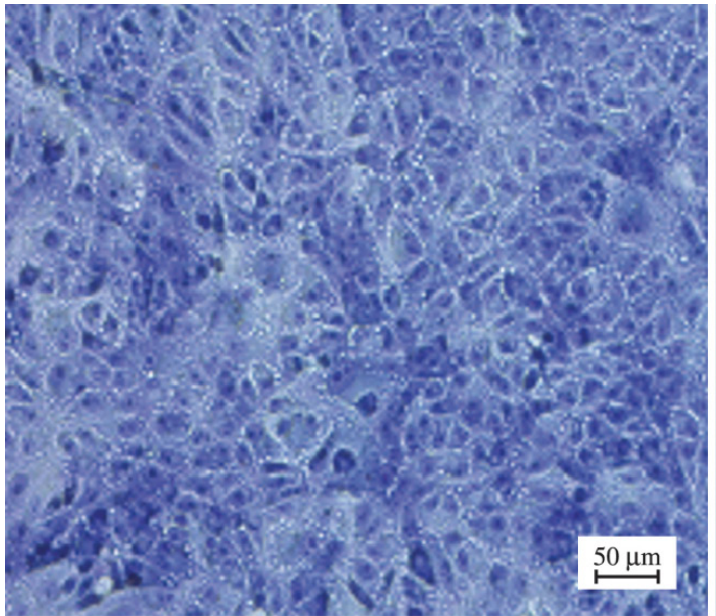

(a)

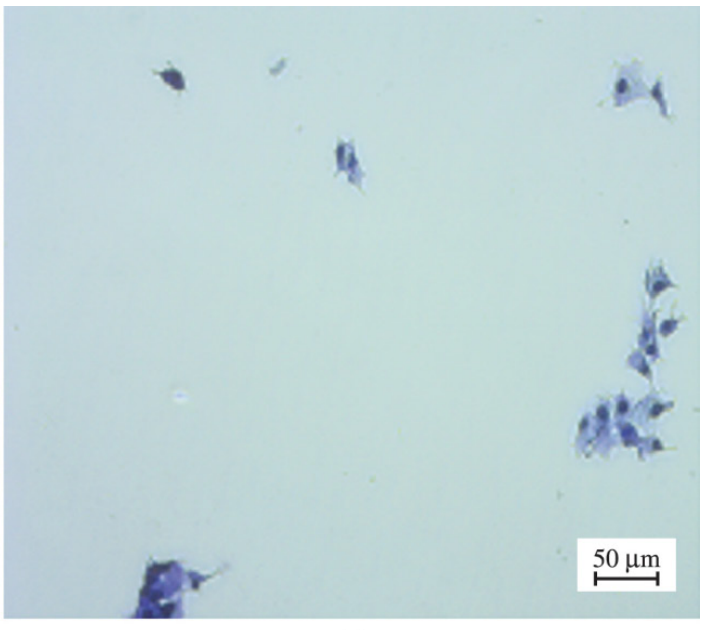

(b)

Figure 12. Test of cytotoxicity controls. (a). noncytotoxic control, confluent monolayer of cells. (b) Control cytotoxic few cells present, with very dense nucleus, cellular prolongations and presence of debris. Cells stained with toluidine blue, increased 200x.

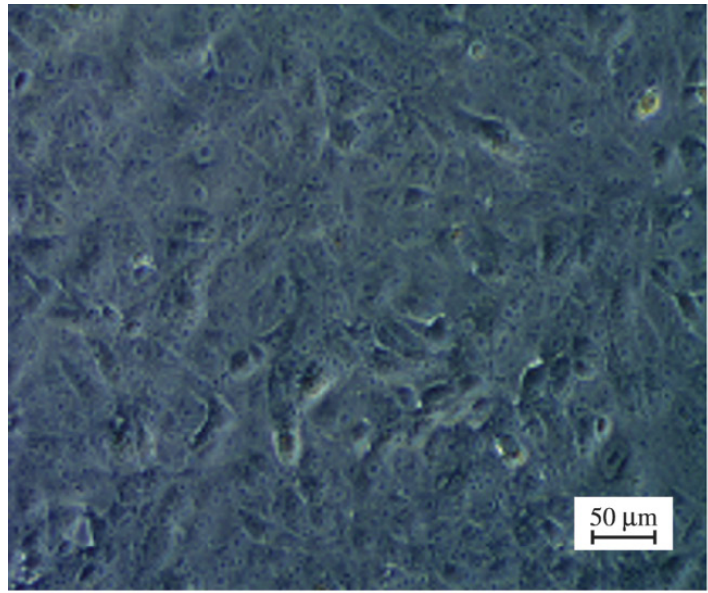

(a)

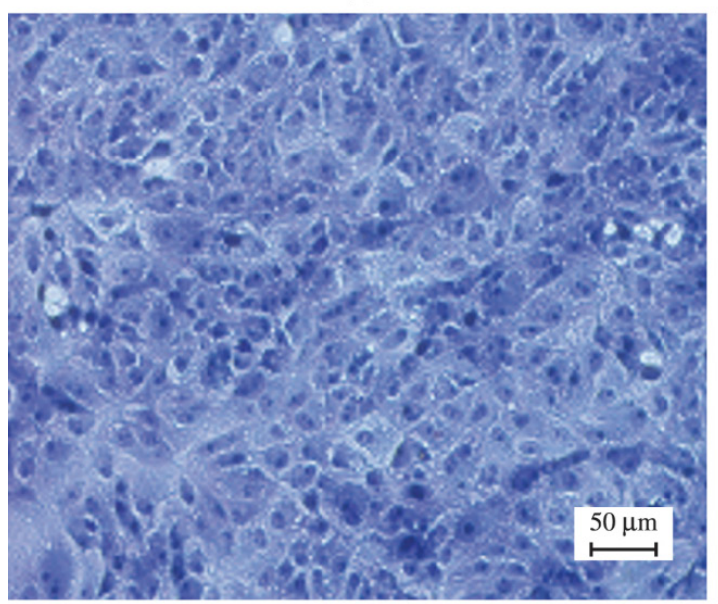

(c)

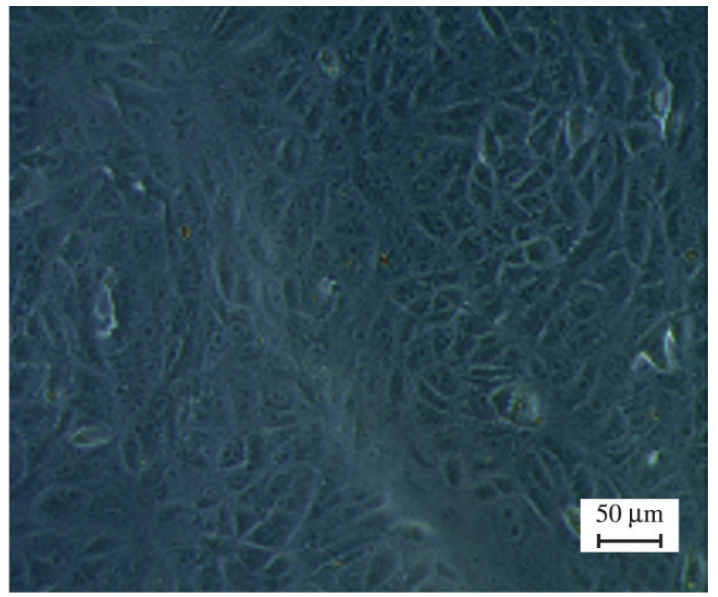

(b)

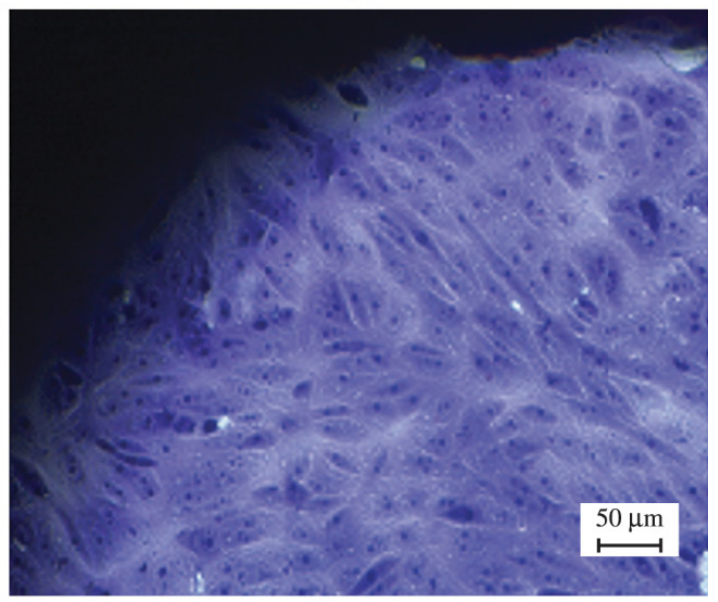

(d)

Figure 13. Test of cytotoxicity biomaterial. (a) Cytotoxicity indirect, phase contrast, (b) Direct contact of the cells with the biomaterial, phase contrast. (c) indirect cytotoxicity, cells stained with toluidine blue (d) Direct contact of the cells with biomaterials, cells stained with toluidine blue. It can be observed the cell monolayer widely scattered, with typical morphology of fibroblasts, even in the limit contact with the biomaterial gelatin / PVP. Increase: 200. 
considered non cytotoxic ${ }^{44,45}$. The growth pattern cytotoxic, with few cells, with extensions, dense core, debris in medium and signs of cellular degeneration was not observed in samples of indirect cytotoxicity of the gelatin biomaterial / PVP. The results obtained with the cell culture in direct contact with the biomaterial proved remarks indirect cytotoxicity. It was possible to observe the same confluent monolayer on the surface of direct contact with the biomaterial with typical fibroblast cells. These results enable future trials to guide the study of cellular interaction with the biomaterial.

In Figure 13a and Figure 13c cultured cells provided indirect cytotoxicity showing growth pattern expected to Vero cells, and consistent with control noncytotoxic. The cells had become quite spread, forming a confluent monolayer with fibroblastic appearance, well-defined nucleus and nucleolus identification of between 1 to 3 per core. There was no cell debris or cell degeneration expressive. In Figures $13 \mathrm{~b}$ and $13 \mathrm{~d}$ the same result can be observed in the test cell culture in direct contact with the biomaterial gelatin / PVP. The cells in the culture dish, and even in areas of direct contact with the biomaterial, kept the typical fibroblast standard without significant signs of degeneration and cell death ${ }^{44,45}$.

The growth of Vero cells in confluent monolayer with typical fibroblast morphology, and similar to control non cytotoxic, shows no cytotoxicity of the gelatin biomaterial / $\mathrm{PVP}^{44,45}$. The growth pattern cytotoxic, with few cells, with extensions, dense core, debris in solution and signs of cellular degeneration was not observed in samples of indirect cytotoxicity of the gelatin biomaterial / PVP. The results obtained with the cultivation of cells in direct contact with the biomaterial proved remarks indirect cytotoxicity. It was possible to observe the same confluent monolayer on the surface of direct contact with the biomaterial with

\section{References}

1. Kulkarni A, Bambole VA and Mahanwar PA. Electrospinning of polymers, their modeling and applications. Polymer-Plastico Tecnologia e Engenharia. 2010; 49(5):427-441. http://dx.doi. org/10.1080/03602550903414019.

2. Wahyudiono MS, Machmudah S, Kanda H, Okubayashi S and Goto M. Formation of PVP hollow fibers by electrospinning in one-stepprocess at sub and supercritical CO2. Chemical Engineering and Processing. 2014; 77:1-6. http://dx.doi. org/10.1016/j.cep.2013.12.007.

3. Kong $L$ and Ziegler GR. Fabrication of pure starch fibers by electrospinning. Food Hydrocolloids. 2014; 36:20-25. http:// dx.doi.org/10.1016/j.foodhyd.2013.08.021.

4. Chew SY, Wen Y, Dzenis Y and Leong KW. The role of electrospinning in the emerging field of nanomedicine. Current Pharmaceutical Design. 2006; 12(36):4751-4770. http://dx.doi. org/10.2174/138161206779026326. PMid:17168776.

5. Huang Z-M, Zhang Y-Z, Kotaki M and Ramakrishna S. Review on polymer nanofibers by electrospinning and their applications in nanocomposites. Composites Science and Technology. 2003; 63(15):2223-2253. http://dx.doi.org/10.1016/S0266-3538(03)001787.

6. Song JH, Kim HE and Kim HW. Production of electrospun gelatin nanofiber by water-based co-solvent approach. Journal of Materials Science. Materials in Medicine. 2008; 19(1):95-102. http://dx.doi.org/10.1007/s10856-007-3169-4. PMid:17577633. typical fibroblast cells. These results enable future trials to guide the study of cellular interaction with the biomaterial.

\section{Conclusions}

In this work, the influence of acetic acid concentration in the electrospinning of galatin/PVP blends from aqueous solutions containing acetic acid was investigated. From the results obtained, it was found that lower concentrations of acetic acid promoted the formation of fibers with smaller diameters, within the concentration range studied. Therefore, the presence of acetic acid has a significant effect on fiber morphology and average diameter.

Solution surface tension and viscosity did not significantly affect the formation of gelatin/PVP fibers. It was found that electrical conductivity was the decisive parameter that highly influenced the resulting fiber diameter.

As expected, it was observed that solutions with higher electrical conductivity produced fibers with smaller diameters. Nanofibers obtained were cylindrical and were randomly distributed in a fibrous mat. In the thermogravimetric analysis of gelatin/PVP, it was observed that the improved thermal stability of the gelatin is attributed to the interaction between gelatin/PVP.

The results obtained from cytotoxicity assays showed that the biomaterial gelatin/PVP showed the expected pattern of growth to Vero cells and no significant signs of degeneration and cell death, which is consistent with the non cytotoxic standard.

\section{Acknowledgements}

The authors acknowledge CAPES, CNPq (306860/2012-0) and INCT-Biofabris for financial support.

7. Garg K and Bowlin GL. Electrospinning jets and nanofibrous structures. Biomicrofluidics. 2011; 5(1):013403. http://dx.doi. org/10.1063/1.3567097. PMid:21522493.

8. Lv N, Ma Q, Dong X, Wang J, Yu W and Liu G. Parallel spinnerets electrospinning fabrication of novel flexible luminescentelectrical-magnetic trifunctional bistrand-aligned nanobundles. Chemical Engineering Journal. 2014; 243:500-508. http://dx.doi. org/10.1016/j.cej.2014.01.022.

9. Sionkowska A. Current research on the blends of natural and synthetic polymers as new biomaterials: review. Progress in Polymer Science. 2011; 36(9):1254-1276. http://dx.doi. org/10.1016/j.progpolymsci.2011.05.003.

10. Chronakis IS. Novel nanocomposites and nanoceramics based on polymer nanofibers using electrospinning process - a review. Journal of Materials Processing Technology. 2005; 167(2-3):283293. http://dx.doi.org/10.1016/j.jmatprotec.2005.06.053.

11. Bhardwaj $\mathrm{N}$ and Kundu SC. Electrospinning: a fascinating fiber fabrication technique. Biotechnology Advances. 2010; 28(3):325-347. http://dx.doi.org/10.1016/j.biotechadv.2010.01.004. PMid:20100560.

12. Chang WM, Wang C-C and Chen C-Y. The combination of electrospinning and forcespinning: effects on a viscoelastic jet and a single nanofiber. Chemical Engineering Journal. 2014; 244:540-551. http://dx.doi.org/10.1016/j.cej.2014.02.001.

13. Okutan N, Terzi P and Altay F. Affecting parameters on electrospinning process and characterization of electrospun 
gelatin nanofibers. Food Hydrocolloids. 2014; 39:19-26. http:// dx.doi.org/10.1016/j.foodhyd.2013.12.022.

14. Sill TJ and von Recum HA. Electrospinning: applications in drug delivery and tissue engineering. Biomaterials. 2008; 29(13):19892006. http://dx.doi.org/10.1016/j.biomaterials.2008.01.011. PMid: 18281090 .

15. Van der Schueren L, Mollet T, Ceylan Ö and De Clerck K. The development of polyamide 6.6 nanofibres with a $\mathrm{pH}$-sensitive function by electrospinning. European Polymer Journal. 2010; 46(12):2229-2239. http://dx.doi.org/10.1016/j.eurpolymj.2010.09.016.

16. Thompson CJ, Chase GG, Yarin AL and Reneker DH. Effects of parameters on nanofiber diameter determined from electrospinning model. Polymer. 2007; 48(23):6913-6922. http://dx.doi. org/10.1016/j.polymer.2007.09.017.

17. Ramakrishna S, Fujihara K and Teo W-E, Lim T-C and Ma Z. An introduction to electrospinning and nanofibers. Singapore: World Scientific; 2005.

18. Yamazaki CM, Kadoya Y, Hozumi K, Okano-Kosugi H, Asada S, Kitagawa K, et al. A collagen-mimetic triple helical supramolecule that evokes integrin-dependent cell responses. Biomaterials. 2010; 31(7):1925-1934. http://dx.doi.org/10.1016/j. biomaterials.2009.10.014. PMid:19853297.

19. Gómez-Guillén MC, Giménez B, López-Caballero ME and Montero MP. Functional and bioactive properties of collagen and gelatin from alternative sources: a review. Food Hydrocolloids. 2011; 25(8):1813-1827. http://dx.doi.org/10.1016/j.foodhyd.2011.02.007.

20. Reis, C. Avaliação da capacidade emulsificante de gelatina acilada. [Dissertation]. Campinas: Universidade Estadual de Campinas; 2003.

21. Schrieber R and Gareis H. Gelatine handbook: theory and industrial practice. Weinheim: WILEY-VCH Verlag GmbH \& Co. KGaA; 2007. 334 p.

22. Sell SA, McClure MJ, Garg K, Wolfe PS and Bowlin GL. Electrospinning of collagen/biopolymers for regenerative medicine and cardiovascular tissue engineering. Advanced Drug Delivery Reviews. 2009; 61(12):1007-1019. http://dx.doi.org/10.1016/j. addr.2009.07.012. PMid:19651166.

23. Parker NG and Povey MJW. Ultrasonic study of the gelation of gelatin: phase diagram, hysteresis and kinetics. Food Hydrocolloids. 2012; 26(1):99-107. http://dx.doi.org/10.1016/j. foodhyd.2011.04.016.

24. Zhang PY, Wang YL, Xu ZL and Yang H. Preparation of poly (vinyl butyral) hollow fiber ultrafiltration membrane via wetspinning method using PVP as additive. Desalination. 2011; 278(1-3):186-193. http://dx.doi.org/10.1016/j.desal.2011.05.026.

25. Panzavolta S, Gioffrè M, Focarete ML, Gualandi C, Foroni L and Bigi A. Electrospun gelatin nanofibers: optimization of genipin cross-linking to preserve fiber morphology after exposure to water. Acta Biomaterialia. 2011; 7(4):1702-1709. http://dx.doi. org/10.1016/j.actbio.2010.11.021. PMid:21095244.

26. Zhi X, Fang H, Bao C, Shen G, Zhang J, Wang K, et al. The immunotoxicity of graphene oxides and the effect of PVPcoating. Biomaterials. 2013; 34(21):5254-5261. http://dx.doi. org/10.1016/j.biomaterials.2013.03.024. PMid:23566800.

27. Karavas E, Georgarakis E and Bikiaris D. Application of PVP/ HPMC miscible blends with enhanced mucoadhesive properties for adjusting drug release in predictable pulsatile chronotherapeutics. European Journal of Pharmaceutics and Biopharmaceutics. 2006; 64(1):115-126. http://dx.doi.org/10.1016/j.ejpb.2005.12.013. PMid:16675210.

28. Xu F, Cui FZ, Jiao YP, Meng QY, Wang XP and Cui XY. Improvement of cytocompatibility of electrospinning PLLA microfibers by blending PVP. Journal of Materials Science. Materials in Medicine. 2009; 20(6):1331-1338. http://dx.doi.org/10.1007/ s10856-008-3686-9. PMid:19160021.
29. Simone S, Figoli A, Criscuoli A, Carnevale MC, Rosselli A and Drioli E. Preparation of hollow fibre membranes from PVDF/ PVP blends and their application in VMD. Journal of Membrane Science. 2010; 364(1-2):219-232. http://dx.doi.org/10.1016/j. memsci.2010.08.013.

30. Hassouna F, Therias S, Mailhot G and Gardette JL. Photooxidation of poly(N-vinylpyrrolidone) (PVP) in the solid state and in aqueous solution. Polymer Degradation \& Stability. 2009; 94(12):22572266. http://dx.doi.org/10.1016/j.polymdegradstab.2009.08.007.

31. Sionkowska A, Wisniewski M, Kaczmarek H, Skopinska J, Chevallier P, Mantovani D, et al. The influence of UV irradiation on surface composition of collagen/PVP blended films. Applied Surface Science. 2006; 253(4):1970-1977. http://dx.doi. org/10.1016/j.apsusc.2006.03.048.

32. Sionkowska A, Kozłowska J, Płanecka A and Skopińska-Wiśniewska JS. Collagen fibrils in UV irradiated poly(vinyl pyrrolidone) films. Applied Surface Science. 2008; 255(5):2030-2039. http:// dx.doi.org/10.1016/j.apsusc.2008.06.200.

33. International Organization for Standardization - ISO. ISO-109935. Biological evaluation of medical devices. Part 5: tests for cytotoxicity: in vitro methods. ISO; 1992.

34. International Organization for Standardization - ISO. ISO11135. Sterilization of health care products - ethylene oxiderequirements for the development, validation and routine control of a sterilization process for medical devices. ISO; 2014.

35. Cameron LC and Machado M. Tópicos avançados em bioquímica do exercício. Rio de Janeiro: Shape; 2004.

36. Gu SY, Wang ZM, Ren J and Zhang CY. Electrospinning of gelatin and gelatin/poly(L-lactide) blend and its characteristics for wound dressing. Materials Science and Engineering C. 2009; 29(6):1822-1828. http://dx.doi.org/10.1016/j.msec.2009.02.010.

37. Geng X, Kwon $\mathrm{OH}$ and Jang J. Electrospinning of chitosan dissolved in concentrated acetic acid solution. Biomaterials. 2005; 26(27):5427-5432. http://dx.doi.org/10.1016/j. biomaterials.2005.01.066. PMid:15860199.

38. Vieira DF, Avellaneda CO and Pawlicka A. Conductivity study of a gelatin-based polymer electrolyte. Electrochimica Acta. 2007; 53(4):1404-1408. http://dx.doi.org/10.1016/j.electacta.2007.04.034.

39. Uyar T and Besenbacher F. Electrospinning of uniform polystyrene fibers: the effect of solvent conductivity. Polymer. 2008; 49(24):53365343. http://dx.doi.org/10.1016/j.polymer.2008.09.025.

40. Davanço, T., Tanada-Palmu, P., Grosso, C. Filmes compostos de gelatina, triacetina, ácido esteárico ou capróico: efeito do $\mathrm{pH}$ e da adição de surfactantes sobre a funcionalidade dos filmes. Revista Ciência e Tecnologia de Alimentos. 2007; 27(2):408-416.

41. Mattos RI. Estudo de condutores protônicos a base de macromoléculas naturais.[Thesis]. São Carlos: Universidade de São Paulo; 2011.

42. Gasaymeh SS, Radiman S, Heng LY, Saion E and Saeed GHM. Synthesis and characterization of silver/polyvinilpirrolidone (Ag/PVP) nanoparticles using gamma irradiation techniques. African Physical Review. 2010; 4(0006):31-41.

43. Han T, Yarin AL and Reneker DH. Viscoelastic electrospun jets: Initial stresses and elongational rheometry. Polymer. 2008; 49(6):1651-1658. http://dx.doi.org/10.1016/j.polymer.2008.01.035.

44. Malmonge SM, Zavaglia CAC, Santos AR Jr and Wada MLF. Avaliação da citotoxicidade de hidrogéis de polihema: um estudo in vitro. Revista Brasileira de Engenharia Biomédica. 1999; 15(1-2):49-54

45. Senne MI, Lemos N, Fidel SR, Fidel RAS. Avaliação da citotoxicidade dos três cimentos endodônticos empregados na obturação do sistema de canais radiculares. Revista Sul Brasileira de Odontologia. 2009; 6(1):71-76. 